Article

\title{
Artificial Intelligence in the Industry 4.0, and Its Impact on Poverty, Innovation, Infrastructure Development, and the Sustainable Development Goals: Lessons from Emerging Economies?
}

\author{
David Mhlanga $(D$
}

check for

updates

Citation: Mhlanga, D. Artificial Intelligence in the Industry 4.0, and Its Impact on Poverty, Innovation, Infrastructure Development, and the Sustainable Development Goals: Lessons from Emerging Economies? Sustainability 2021, 13, 5788.

https://doi.org/10.3390/su13115788

Academic Editors: Sanghyo Lee and Luigi Aldieri

Received: 13 April 2021

Accepted: 12 May 2021

Published: 21 May 2021

Publisher's Note: MDPI stays neutral with regard to jurisdictional claims in published maps and institutional affiliations.

Copyright: (C) 2021 by the author. Licensee MDPI, Basel, Switzerland. This article is an open access article distributed under the terms and conditions of the Creative Commons Attribution (CC BY) license (https:// creativecommons.org/licenses/by/ $4.0 /)$.
Department of Accountancy, University of Johannesburg, Auckland Park, P.O. Box 524, Johannesburg 2006, South Africa; dmhlanga@uj.ac.za

\begin{abstract}
Artificial intelligence in the fourth industrial revolution is beginning to live up to its promises of delivering real value necessitated by the availability of relevant data, computational ability, and algorithms. Therefore, this study sought to investigate the influence of artificial intelligence on the attainment of Sustainable Development Goals with a direct focus on poverty reduction, goal one, industry, innovation, and infrastructure development goal 9, in emerging economies. Using content analysis, the result pointed to the fact that artificial intelligence has a strong influence on the attainment of Sustainable Development Goals particularly on poverty reduction, improvement of the certainty and reliability of infrastructure like transport making economic growth and development possible in emerging economies. The results revealed that Artificial intelligence is making poverty reduction possible through improving the collection of poverty-related data through poverty maps, revolutionizing agriculture education and the finance sector through financial inclusion. The study also discovered that $\mathrm{AI}$ is also assisting a lot in education, and the financial sector allowing the previously excluded individuals to be able to participate in the mainstream economy. Therefore, it is important that governments in emerging economies need to invest more in the use of AI and increase the research related to it so that the Sustainable Development Goals (SDGs) related to innovation, infrastructure development, poverty reduction are attained.
\end{abstract}

Keywords: artificial intelligence; Industry 4.0; innovation; infrastructure development poverty; Sustainable Development Goals

\section{Introduction}

Industry 4.0 or the fourth industrial revolution (4IR) is gaining a lot of attention particularly on its potential impact on humanity [1]. Schwab [1] argued that 4IR will change how human beings live, work and how the economies work as well as how we are governed. It is also believed that the industrial revolutions began as far as the 17th century with Britain being the major player with what came to be known as the first industrial revolution $[2,3]$. The word "industrial revolution can be described as economic upheaval" which necessitated the changes in the "livelihood of the people from agrarian rural livelihood to city and town livelihood" [3]. According to Blinov [2] before the coming in of the first industrial revolution championed by Britain, economic activities were limited and as a result, many people were poor and human livelihood was sustained by what people get from the small farms which made life for an average person to be difficult [4].

During this period production was mainly for their consumption, as a result, people were using basic tools which were mainly hand tools for production and production was mainly confined in people's homes $[3,4]$. The coming in of the first industrial revolution marked the replacement of animal power to the steam engine which marked the "shift from agrarian livelihood" to industrialization where "special-purpose machinery" was now used 
kickstarting the first industrial revolution in Britain at the beginning of the 18th century [5]. The steam engine allowed the production of goods and services to be mechanized for the first time deriving social change as people became increasingly urbanized [5]. Products like textiles, iron rail transport, coal among others became common in the first industrial revolution. On the other hand, the second industrial revolution started with the expansion of electricity steel industries and petroleum industries and other scientific achievements that led to mass production [6,7].

Around the 1950s, the third industrial revolution began with the inventions of computers and digital technology allowing the manufacturing sector to be automated. However, the inventions of the third industrial revolution came fourth with disruptions in various industries which include banking, energy, and communications. Ooi et al. [7] argued that despite the disruptions, the technologies opened some doors in areas of space research and biotechnology opening opportunities for many people who were affected by the disruptions. Various scholars such as Schwab [6], Ooi et al. [7] (2018), Radziwill [8] 2018 believe that we are currently in the 4IR or Industry 4.0 also known as the fourth industrial revolution. The three industrial revolutions became the basis or the foundation of Industry 4.0 which was defined by Schwab [6] as:

"The blurring of boundaries between the physical, digital, and biological worlds. It is also viewed as the fusion of advances in artificial intelligence (AI), robotics, the Internet of things (IoT), 3D printing, genetic engineering, quantum computing, and other technologies Industry 4.0 is the collective force behind various products that are fast becoming indispensable to modern life through the application of AI and machine learning. Products like the GPS systems that suggest the fastest route to a destination, the ability of Facebook to recognize human faces as well as your face and tag a person in a friend's photo".

Nations all over the world are preparing and make serious plans for the impact of this revolution on humanity, economies and even businesses and the literature of the influence of Industry 4.0 on society through the 1 is developing, this area has not been deeply researched especially the impact of AI on poverty reduction, infrastructure development and the general attainment of the SDGs [8-10]. All the previous industrial revolutions led society to go: "through painful processes of adaptation, for example from rural, largely agricultural societies, to urban, industrial societies, and then to post-industrial societies dealing with the loss of traditional industries and sources of employment" [2]. At the same scholars argue that the impact of the 4IR on society will result not only in the loss of jobs but a marginal shift in how public and private goods and services are delivered $[3,11]$.

Smith [12] in a study getting value from artificial intelligence in agriculture, stated that $\mathrm{AI}$ is beginning to live up to its promises of delivering real value due to the availability of relevant data, computational ability, and algorithms. Smith [12] also argued that AI applications can help to improve productivity in farming by improving the detection of diseases and the precision of measurements about what is happening on the farm. EliChukwu [13] in another study indicated that the usefulness of AI applications has been evident in the agricultural sector. In the study, Eli-Chukwu [13] stated that AI plays critical role to solve some of the challenges affecting the agricultural sector especially the ability of farmers to maximize yields. Therefore, the purpose of this study is to investigate the influence of AI on the attainment of SDGs with a direct focus on poverty reduction, goal one, industry, innovation, and infrastructure development goal 9, in emerging economies.

\section{The Industry 4.0 the Fourth Industrial Revolution}

Industry 4.0 is unique when it is compared to other previous Industrial Revolutions [1]. According to Schwab [6], Industry 4.0 has dramatic differences from the other three industrial revolutions due to the scale, scope, complexity, and its transformation, which will be unique to all other revolutions. Schwab [6] argued that the revolution will be something humankind has never experienced before because it is not just an extension of the previous industrial revolution, but it is a new distinct revolution $[6,10]$. The first notable difference 
of Industry 4.0 to other past revolutions is the production of information where people can come up with new information as well as generating new knowledge in the mining of information $[6,10]$ This is enhanced by the possibilities available for many people to be connected by mobile gadgets with strong processing power, storage capacity, and unlimited access to knowledge [14,15]. In a way, the continuous data accumulation and analysis is permitting the intelligence of machines to improve.

The other issue which makes Industry 4.0 to be unique from other industrial revolutions is the fact that Industry 4.0 is not just massive advances in technology but it will also come with a transformation of the existing relationships in the production process $[16,17]$. Industry 4.0 is also allowing the manufacturing sector to be in the class of the information age through permitting communication at all the stages of production. Some scholars also believe that Industry 4.0 is coming up with new economic formations in various sectors of the economy such as the sharing economy where services like transport, toys, basketballs are being shared $[15,18]$.

On the other hand, some researchers believe that Industry 4.0 will result in more inequality due to its threat of disrupting labour markets. It is argued that the continuous growth in automation, robots and computers will take the jobs of workers in many industries with the most worrying factor being the increased danger of the disappearance of low-skill/low-pay jobs which will cause a lot of challenges for the poor which will lead to a rise in social tensions [10,19]. However, Schwab, [6] argued that in its strict sense, the issue of inequality is not unique to Industry 4.0, in history, all other previous revolutions always started with huge inequality followed by periods of political and institutional change. However, the most worrying fact is that in Industry 4.0 it is not only the movement of labour from one sector of the economy to another but the existence of robots and computers that will replace human capital in short, taking the jobs of people $[1,6]$. The other aspects the technological revolution will have an impact on are issues related to material or ideological changes caused by the introduction of new devices or new systems which will have an impact on reshaping the culture of humankind. Figure 1 below explains the four industrial revolutions from the first to the current revolution.

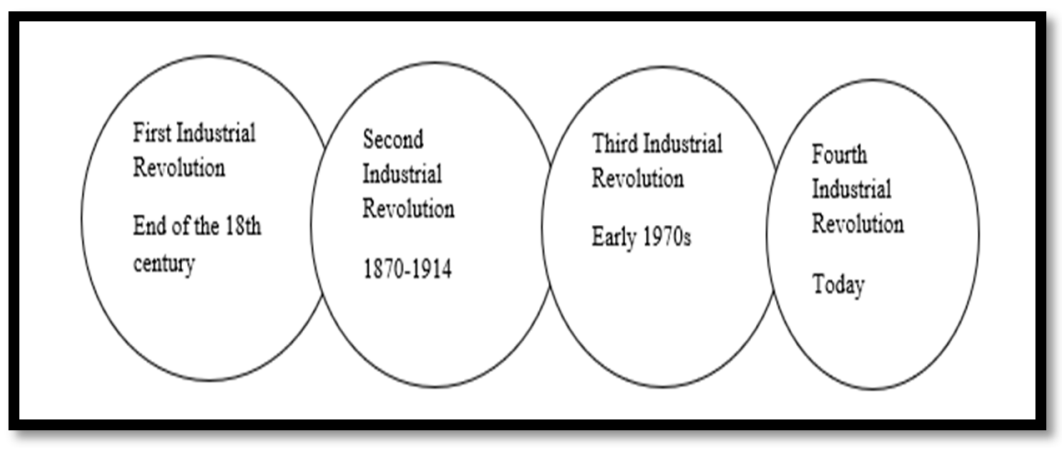

Figure 1. The Four Industrial Revolutions. Source: $[9,20]$.

The four industrial revolutions are clearly shown in the diagram above from the first industrial revolution to the last industrial revolution of today. The first industrial revolution started towards the end of the 18 th century followed by the second industrial revolution which happened between 1870 and 1914. In the early 1970s, the third industrial revolution happened. The fourth industrial revolution is happening today with various technologies that are driving it such as AI, robotics, blockchain, distributed ledger technology among several other technologies.

\section{Literature Review}

\subsection{A Brief History and Definition of AI}

The Idea behind the subject of AI began in 1955 with John McCarthy who assumed that all the aspects of learning and the notable domains of intelligence can be simulated 
by a machine [8,20]. On the other hand, Haenlein and Kaplan [21] stated that "although it is difficult to pinpoint the roots of AI, however, it is possible to trace back to the 1940s, specifically 1942, when the American Science Fiction writer Isaac Asimov published his short story Run around. The plot of Run around a story about a robot developed by engineers. The word "Artificial Intelligence" was then officially coined in 1956 Marvin Minsky and John McCarthy one of the computer scientists at Stanford".

The term artificial intelligence is explained as:

"The investigation of intelligent problem-solving behaviour and the creation of intelligent computer systems. In other words, AI describes the work processes of machines that would require intelligence if performed by humans" [20].

As outlined by Wisskirchen et al. [20] AI has two kinds which are weak AI and strong AI. With weak AI "the computer is merely an instrument for investigating cognitive processes the computer simulates intelligence". Strong AI, on the other hand, entails "the processes where computers are intellectual, self-learning processes. Computers can understand through the right software/programming and can optimize their behavior based on their former behaviour and their experience" [20]. Strong AI includes automatic networking with other machines, which leads to a dramatic scaling effect [22]. The most notable economic disciplines of AI are deep learning, robotization, dematerialization, the gig economy and autonomous driving cars among others [20].

Benko and Sik Lányi [23] insinuates that even though AI has been studied for decades but it is still one of the most elusive subjects in computer science because the subject is large and nebulous. It is believed that AI ranges from machines that can think to search algorithms used to play board games. In other words, it is insinuated that AI has applications in nearly all ways humans use computers in society. AI is used in subtler ways which include examining purchase histories as well as influencing marketing decisions [23]. According to Buchanan [22] robots have always been part of the public's perception of intelligent computers, but early robotics efforts had more to do with mechanical engineering than with intelligent control. However, through the power of AI robots are becoming more powerful vehicles for the testing idea across the world about intelligent behaviour. However, it has been argued that AI is not just about robots. It is also about understanding the nature of intelligent thought and action using computers as experimental devices [22].

\subsection{The Theoretical Definitions of Poverty}

Poverty over the years has been defined with a bias towards monetary aspects, however, with time scholars are beginning to shift the definition of poverty to multidimensional issues like political participation and social exclusion showing that poverty is a multidimensional phenomenon [24] (Davis and Sanchez-Martinez, 2014). This means that poverty is not a direct result of one factor but a combination of factors. As a result, the United Nations (UN) defined poverty in two aspects which are absolute poverty and overall poverty. Absolute poverty is defined as a condition where people are deprived of basic human needs like food, health, shelter, safe drinking water, sanitation facilities, education, and information [25,26]. As a result, poverty is because of many factors, not only income [26]. Overall poverty is defined as a condition where people are not able to have access to income and other productive resources. Overall poverty is characterized but not limited "to hunger and malnutrition, ill-health, inability to access education, a rise in morbidity and mortality from illness, shortage of housing, unsafe environments, social exclusion and discrimination" [24]. Overall poverty also "involves a lack of participation in decision making in civil, social and cultural life" [27].

The UN also came up with another definition of poverty, the multidimensional poverty index [26]. The definition by the UN in 2010 involves many issues such as education, health, standards of living and many other variables. In 2013, the Joseph Rowntree Foundation (JRF) defined poverty as a condition where people's material resources are not enough to satisfy the minimum needs with social participation is included [26,28] (Mhlanga, 2020b, Mhlanga, and Ndhlovu). The World Bank stressed much on consumption and income 
of individuals as major variables which can render a person to be poor especially if the individual fails to reach a prescribed income or consumption threshold commonly known as the poverty datum line [26]. From the various definitions of poverty, the study will investigate how AI can have an impact on poverty from various dimensions.

\subsection{Poverty Statistics in The World}

The battle against poverty is going on the world over, although there was a decline in global extreme poverty, the pace is slow. The portion of the population in the world living in extreme poverty declined to $10 \%$ in 2015 , down from $16 \%$ in 2010 and $36 \%$ in 1990 [29,30] (Guterres, 2019; World Bank, 2019). The statistics show that the world is not on track in attaining the goal of reducing the world's population living in extreme poverty by 2030 [30]. However, the baseline projections suggest that $6 \%$ of the world population will still be living in extreme poverty in 2030, missing the target of ending poverty [29] (Guterres, 2019; World Bank, 2019). People who live in extreme poverty continue to face deeply entrenched deprivation which is sometimes exacerbated by violent conflicts and vulnerability to disasters. It is argued that tough social protection systems and massive government spending on key services can help those in poverty to come out of the poverty brackets. However, there is a need for strengthening and scaling up these services [29] (Guterres, 2019). According to Guterres [29] despite having a job 8 per cent of households are still living in extreme poverty in the year 2018 [29]. The situation is worse in SubSaharan Africa where a portion of the poor working population is approximately 38 pecent in 2018 [29].

The World Bank also supported the fact that poverty is still concentrated in SubSaharan Africa. In 2019 the World bank Indicated that despite a decline in poverty rates in all the regions in the world, but the rate of progress was uneven [30]. The World Bank estimated that approximately more than half of the extremely poor people live in SubSaharan Africa [30]. In 2015, it was also estimated that the portion of poor households in Sub-Saharan Africa rose by 9 million, while 413 million people are surviving on less than US\$ 1.90 a day. This was more than all other regions in the world combined [26,30]. It is also believed that if the trend continues, by 2030, nearly 9 out of 10 extreme poor will be in Sub-Saharan Africa [31]. The other worrying aspect is that the bulk of poor people in the world reside in rural areas. Most of these people are poorly educated, employed in the agricultural sector, and under 18 years of age as articulated by the World Bank [30,32]. The World Bank also indicated that the work to end extreme poverty is still in progress with many challenges present due to slow growth rates in many parts of the world [30,31]. This study, therefore, intends to investigate how can the use of AI help to address the problem of poverty which is affecting the whole world.

\subsection{Empirical Literature Review}

The subject of AI and poverty is relatively new because the empirical literature on the impact of AI on poverty is still scarce. Smith [12] in a study getting value from artificial intelligence in agriculture reasoned that $\mathrm{AI}$ is beginning to live up to its promises of delivering real value due to the availability of relevant data, computation, and algorithms. In the study, Smith [12] discusses the value of agriculture from AI in the next decade. In the study, it was discovered that AI applications can help to improve productivity on the farm through improving the detection of diseases and the precision of measurements about what is happening on the farm. The study also indicated that in many cases robotics and automated systems will remove much of the need for human decision-making and improve farm efficiencies and farm health. AI also helps the farmers to harness the value of information distributed throughout supply chains, including farm data.

In another study, Dharmaraj and Vijayanand [33] argued that the fact that the population is increasing estimated to increase by 2 billion in 2050, means that AI is important to improve the efficiency of farming practices. Dharmaraj and Vijayanand [33] also indicated that a direct application of AI or machine intelligence across the farming sector could act to 
be an epitome of the shift in how farming is practiced today. The study also highlighted that farming solutions that are AI-powered, on many occasions, enable a farmer to do more with less, which enhances the quality, also ensuring that farmers will go to markets very fast that enhancing quick GTM (go-to-market strategy) strategy for crops.

Again Vincent et al. [34] argued that the world population is expected to increase to 2 billion in 2050, while the arable area is expected to grow by only 5\%. As a result, smart and efficient farming techniques powered by AI and machine learning are necessary to improve agriculture productivity. The study also highlighted that the suitability of agricultural land is among several critical tools that drive agricultural development. As a result, AI performs a big role in agriculture an alternative in the collection and processing of information through wireless sensor networks. The availability of wireless sensor networks is also allowing the development of low-cost sensor devices with the Internet of Things (IoT) with the power of being appropriate tools for automation and decision making in agriculture. Vincent et al. [34] believe that integrating sensor networks with AI systems Like neural networks and Multi-Layer Perceptron (MLP) can help assess the appropriate land for agricultural purposes.

Eli-Chukwu [13] in another study indicated that the application of AI has been evident in the agricultural sector. In the study, Eli-Chukwu [13] stated that AI plays critical roles to solve some of the challenges affecting the agricultural sector in their endeavor to maximize yields. Some challenges affecting the agricultural sector where AI can play a critical role is to ensure that there are proper soil treatment, disease, and pest infestation control, ensuring that big data requirements are solved, problems of low output can also be addressed, and knowledge gap between farmers and technology can be reduced. Eli-Chukwu [13] stated that AI can help to solve some of these challenges in agriculture due to its flexibility, high performance, accuracy, and cost-effectiveness.

Zavadskaya [35] investigated the application of AI finance particularly issues to do with portfolio management, bankruptcy prediction, credit rating, exchange rate prediction and trading. The main idea objective of the study was the stock market prediction, and whether Artificial Neural Networks (ANN) as proxies for AI, could offer an investor more accurate forecasting result. Zavadskaya [35] discovered that ANN performed well in the prediction of results for investors compared to many models. The study also discovered that combining AI with the concept of big data, Google Trends search as a measure of market sentiment is valuable in the modelling of returns. Cossy-Gantner et al. [36] also stated that the field of AI has been developing in the last 60 years and various applications of AI have been utilized in high-income countries and their use in poor countries is still a huge challenge. Cossy-Gantner et al. [36] went on to argue that even though AI still has problems in its application in low-income countries it is present huge promises in the transformation of healthcare in poor nations.

Kliestik et al. [37] also empirically examined the fourth industrial revolution manufacturing systems with data collected from various companies such as Deloitte, McKinsey among others at the same time Peters et al. [38] carried an empirical study to evaluate and analyze sustainable Industry 4.0. The study made use of data collected from various companies just like Kliestik et al. [37] and all the studies did find the importance of AI. Just like Kliestik et al. [37] and Peters et al. [38]. Yigitcanlar et al. [39] discovered that urban innovation through $\mathrm{AI}$ is growing smart cities where urban locations are being enabled by the community, technology, and policy to influence productivity, innovation, sustainability, good governance, and good planning powered by AI. Yigitcanlar et al. [39] also found out that research on AI from the perspective of smart cities is still emerging and more researchers are focusing on AI technologies, algorithms, and their prospective applications. Yigitcanlar et al. [39] also discovered that there is limited research on the risks of the utilization of AI and the future disruptions of AI on cities has not been investigated fully.

How et al. [40] also came up with a study to assess the no-coding human-centric AI-based approach in the analysis or prediction of the intentions of the financial products offered. How et al. [40] found that financial service providers must understand the na- 
ture and behaviour of the underserved communities for them to save them successfully. How et al. [40] believed that applying AI on legacy data is critical to assist financial service providers to anticipate how prospective customers respond when they are approached with products. The study by How et al. [40] found out that a key factor in poverty reduction is financial inclusion powered by AI, but it has been discovered that financial service providers who do not know about computer programming to implement AI projects continue to experience challenges.

\section{Research Methodology}

The study used secondary research to investigate the influence of AI on the attainment of SDGs with a direct focus on poverty reduction, goal one, industry, innovation, and infrastructure development goal 9, in emerging economies. To analyze the impact of AI on the attainment of the SDGs objectively the study used unobtrusive research techniques. Elo et al. [41] defined unobtrusive research as the methods of data collection where the researcher does not interfere with the subjects under investigation. This is mainly because the methods are not obtrusive [42]. The study made use of content analysis which is the study recorded information in texts, media, or physical items. In other words, content analysis is a research technique used in the determination of the availability of certain words, themes, or concepts within some given qualitative data text or data. The content analysis allowed the study to quantify and analyze the presence, meanings and relationships of such certain words, themes, or concepts that acted as the basis for the arguments and conclusion of the study. Secondary sources of data like governments reports, international statistics, media articles, peer-reviewed journal articles, books were critically reviewed to inform the discussions in the paper. The main limitation of the current study is the fact that some of the official complex hard data and peer-reviewed journal articles and books on the influence of AI on poverty, innovation, infrastructure development and sustainable development is still developing. However, the author tried to utilize the available information that was published by scholars, private organizations, and governments through various organizations. The advantage of content analysis is its non-invasive nature when analyzing a social phenomenon [42]. Content analysis is used in specifically three different approaches which include the conventional, directed, and summative. According to Elo et al. [41], the three approaches help in the interpretation of meaning from the content of text data permitting them to conform to the naturalistic paradigm. The current study was mainly premised on the summative content analysis involves the counting and comparisons of keywords and interpret the context in the keywords or content, followed by the interpretation of the underlying context [42].

\subsection{Discussion of the Impact of AI on Poverty, Innovation, and Infrastructure Development}

AI technologies can play a central role in the achievement of the Sustainable Development Goals (SDGs). This study is assessing the impact of AI on poverty, which is goal one of the Sustainable development goals, end poverty in all its manifestations and goal 9 Industry, innovation, and infrastructure development.

\subsection{The Role of AI in Industry, Innovation, and Infrastructure Development}

One of the critical components of economic growth and development is an investment in infrastructure and innovation [43]. It is estimated that over half of the world's population is living in cities, making infrastructure development and innovation in mass transport and renewable energy very critical [44]. Conde and Twinn, [44] went on to argue that the massive growth in the population in cities also makes the growth of new industries, the growth of information and communication technologies (ICT) and AI very critical. The other stubborn fact is that more than 4 billion people do not have internet access and over 90 per cent of these people are found in the developing world [45]. The only way to bridge this digital divide is to make sure that there is massive infrastructure development, a massive increase in access to information and knowledge as well as fostering innovation 
and entrepreneurship powered by AI [45]. It is also believed that 2.3 billion people the world over cannot access basic sanitation due to infrastructure constraints which cut business productivity in many low-income African countries by approximately $40 \%$ [46]. The United Nations also reported that approximately 2.6 billion people in developing nations do not have access to constant electricity and the renewable energy sectors currently employ more than 2.3 million people which is predicted to rise to 20 million by 2030 [47]. The other serious problem that manifests because of the lack of proper infrastructure is that barely 30 per cent of agricultural products in developing countries went through industrial processing as compared to $98 \%$ in high-income countries $[46,47]$

According to Conde and Twinn, [44] AI is now changing the world economy and it is estimated that advances in AI could add approximately 13 trillion to global economic output by 2030. In the transport sector, the global market for transport-related AI technologies reached $\$ 1.2$ to 1.4 billion and it is estimated to grow to 3.1 and 3.5 billion by 2023 which is a 12 to 14.5 growth from 2017 to 2023 [44]. Various AI interventions can be applied to various sectors to improve the infrastructure, for instance, the transport sector, agriculture which can transform these sectors towards the attainment of the SDGs. The World Bank stated that the applications of AI in the transport sector go beyond driverless vehicles but can solve various problems related to safety for drivers and pedestrians. Road traffic accidents are one of the health hazards especially in developing countries Conde and Twinn, [44] (2019) reported that road traffic-related deaths reached 1.35 million in 2016 up from 1.25 million in 2013 and most of the accidents happened in low-income nations. Some of the reasons given are inadequate infrastructure, poor roads, and vehicles without modern safety equipment as well as human error.

One of the reports by Conde and Twinn, [44] reported stated that in the European Union (EU) human error, speeding, distraction, and drunk driving contributes to more than 90 per cent of all the accidents on roads. In 2017 alone approximately 25,000 people lost their lives in these accidents in the EU. Research is pointing to the fact that the application of AI through autonomous vehicles can help to reduce traffic accidents by approximately $90 \%$ by 2050 in some developed nations. The first attempt by Tesla at an autonomous vehicle reduced accident rates by 40 per cent the moment self-driving technologies were activated. It is a fact that though autonomous vehicles will bring some benefits, the deployment in emerging markets will take a long time, but some researchers project that there will be 1 driverless car in every 4 cars in 2030.

The other aspect where AI is doing a lot is the improvement of the certainty and reliability of infrastructure, especially in the transport sector. The World Bank reported that one enabler of the safe and efficient movement of goods and people the ability to be able to forecast arrival and departure times. Companies such as Uber and Lyft are using AI applications in different ways to offer the much-needed reliability pickup and drop-off times for their routes. So, these AI applications can be applied to improve the quality of public transport solutions globally. One example is Via a company in New York city in America which is giving licenses to its technology to the New York City Department of Education to come up with designs of smart bus routes which will provide transparency on pickups and drop-offs. AI is also playing a crucial role in maintaining the environment, for instance, in the transport sector AI technology can reduce the number of inefficient trips at sea and on the road through the optimization of routes to improve fuel efficiency and reduction of greenhouse gases emissions. It was estimated that the world over $23 \%$ of total energy-related carbon dioxide emissions. One of the eco-friendly AI application is well known as truck platooning which is a technique that can successfully connect several trucks wirelessly to a lead truck permitting them to operate much closer to each other safely, realizing fuel efficiency.

In emerging markets, we have several case studies where AI is being used to improve industries and infrastructure. Many cities in the world are using AI to assist solve traffic flow challenges. In India, a city called Bengaluru Siemens mobility came up with a monitoring system that makes use of AI through traffic cameras to detect and calculate the 
density of traffic on the road and then through the power of AI the traffic lights will be altered based on real-time road congestion. The other example is Alibaba one of China's e-commerce companies introduced the City Brain to try and improve efficiency and reduce road congestion through utilizing data from traffic lights, closed-circuit television (CCTV) camera as well as video recognition to suggest traffic flow management. The other case study is of the two Chinees companies China Post and Deppon Express that are in logistics, they are using AI driving technology from Fabu to introduce autonomous trucks on Chinee's roads. These trucks were tested, and they become successful on level 4 autonomy which implies that they can operate on selected conditions without human input.

Drones are also another classical example of the application of AI especially in places where there is no infrastructure like Sub-Saharan Africa where drones are being used in healthcare. Rwanda is one of the countries where the commercial drone was launched for commercial drone delivery service. Drones are used to fly medical supplies such as blood. One example is An American start-up Zipline which partnered with the government of Rwanda to lunch the first commercial drone delivery service, flying medical supplies faster than road transport. The other example that was given is the China start-up Sichuan Tengden Technology which developed a drone with the capacity to carry 20 tons of cargo and it can fly up to $7500 \mathrm{~km}$. Apart from drones, many countries are developing smart airports that are making use of intelligent navigation systems with the ability to do facial recognition and big data analysis for a paperless and more efficient experience.

\subsection{Poverty Mapping and Poverty Data Collection}

The World Bank estimates that 736 million people live in extreme poverty worldwide, and half of them are in just five countries which are India, Nigeria, the Democratic Republic of Congo, Ethiopia, and Bangladesh. The World Bank and the UN in their fight against poverty rely heavily on research and data to measure progress towards this goal [48]. Strusani and Houngbonon [43] in their study indicated that AI technologies are coming up with new and efficient ways of monitoring and evaluating development interventions that are meant to target the poor and those in need. One of the problems that affect emerging economies is the fact that they lack the data which is critical to fine-tuning the development interventions [43] (Strusani and Houngbonon, 2019b). AI is now coming in with the capacity to make use of unstructured data such as images, texts as well as audio o come up with the information required to improve the various outcomes of development. The Decentralized AI Alliance in 2020 reported that the impossibility to collect data is a consequence of poverty itself. The organization went on to report that the location of the people that are in poverty or need is a fundamental variable that needs to be taken seriously in the objective to end poverty in all its forms everywhere [49]. It is believed that countries are not collecting as much data and scaling up traditional household surveys to identify the number of poor people and the regions where these people are located. This is also worsened by the fact that traditional household surveys are expensive to many nations [49].

However, AI can assist to change this. A recent study by a team at Stanford University is using satellite images to provide an alternative to map poverty [50]. The study focused on five Africana countries namely, Nigeria, Tanzania, Uganda, Malawi and Rwanda social scientists and computer expert came up with the idea of using high-power satellites to detect poverty through an analysis of their images. In a way to corroborate the predictions from the study, the researchers used accurate survey data [50]. In a way to effectively map poverty, AI can combine high-resolution satellite imagery with powerful machine learning algorithms and predict how rich or poor specific locations around the world are. AI can help to effectively provide information like the distance from the nearest water sources, the nearest urban market or where the agricultural fields are, and many other important variables used when measuring poverty [49].

The Qatar Computing Research Institute (QCRI), which is part of Hamad Bin Khalifa University, is also collaborating with several organizations such as the World Bank and 
UN to tackle poverty among other global problems using AI [48]. QCRI also developed the AI for Digital Response (AIDR) platform, which analyses data during disasters, such as the hurricanes like Hurricane Dorian. These analyses help a lot to map the areas where help is needed the most and the level of effort needed to respond to a disaster [48]. The QCRI also work directly with relief organizations in the development of technologies used in the analysis of big data in times of disaster in a way to analyze the conditions for the allocation of resources [48]. With machine learning, the QCRI is producing poverty maps by utilizing anonymous advertising data from Facebook [48]. In India, there was the use of machine learning on value-added tax data to improve the targeting of firms for audits. AI application was also used in predicting travel demands after the hurricane in India and to assess where food insecurity will mostly occur to improve target interventions.

\subsection{The Impact of AI on Agriculture in Rural Areas}

The definition of poverty as highlighted before is a multifaceted phenomenon in other words poverty is multidimensional. It manifests itself in lack of income, lack of education and sometimes lack of social assistance and even food insecurity [49]. This mostly affects rural areas where most of the poor people reside. According to the World Bank, agriculture is the source of livelihood in areas where poverty is more prevalent [51]. Strusani and Houngbonon [43] reported that AI application can address the various challenges that are faced by the people at the bottom of the income distribution especially the bottom $40 \%$. Even though most of the poor people cannot purchase AI-enabled equipment, it has been argued that these people can directly benefit from AI through AI service solutions through their mobile devices. The practical example is the machine learning application, Nuru that was used in the agricultural sector in Kenya, Mozambique, and Tanzania. This application was used in farms in the identification of leaf damage in photos taken by farmers that were sent to authorities to assist in monitoring the presence of one of the evasive pests that have been threatening the revenue of farms and food security across East Africa.

The other importance of $\mathrm{AI}$ is the fact that the data generated from mobile phones can be highly correlated with the financial status, education level as well as health status. This can allow mobile applications to deliver microlending, the establishment of personalized tutoring, the diagnosis of health and medication advice. The critical use of AI applications is the removal of literacy barriers among the poorest individuals through AI speech recognition and speech to text functionalities, especially when accessing text-based applications. In most rural areas that are far from the urban areas AI through image recognition can be used in the assessment of microinsurance claims of farmers. All these AI application among the farmers help to improve productivity which will allow them to improve their revenue and to become food secure. The Decentralized AI Alliance in 2020 also reported that AI can address the problem of poverty through improving farming soil cultivation for growing crops and the rearing of animals as a way of providing food and other important products. Through AI applications robots can now help farmers to harvest crops and predicting the best ways for farmers to grow different crops [49].

Schmidt [50] also stated that using robotics, $\mathrm{AI}$ is becoming an important variable in solving world hunger. Schmidt [50] believes that there is progress being made by corporations and university programs such as Google and Stanford University's Sustainability and Artificial Intelligence Lab. These organizations are coming forth with AI programs in agriculture which are doing a lot to improve farming, helping in the identification of diseases, prediction of crop yields and location of areas prone to scarcity. One example where AI is being applied is through FarmView programme created by researchers from Carnegie Mellon University (CMU) to help farmers to grow more food using the same number of crops. This effort is being applied to come up with rapid solutions to the critical problem of paid rise in population. It is estimated that by the year 2050, approximately 9.8 billion people will live on the planet, and this will increase food scarcity making this topic very critical. However, the availability of AI will help to improve farming methods sensing and robotics technologies to improve plant breeding and crop management [50]. 
Researchers are busy collecting a lot of information using drones, robots, and stationary sensors to increase yields of drought and heat resistant crops that can thrive in famine-stricken nations $[49,50]$. Through AI technology researchers and machine learning technologies data is analyzed to determine what factors yield more sorghum $[49,50]$.

Another example of where AI is helping a lot in agriculture is through industry PlantMD. PlantMD is an application created by high school students Shaza Mehdi and Nile Ravanell in Georgia United States of America. This application allows a farmer to detect plant diseases [50]. This application was built using Google's TensorFlow, an open-source machine learning library [50]. The PlantMD application was influenced by Nuru one of the applications built by a research team at Penn State University Pennsylvania called Plant Village alongside the International Institute of Tropical Agriculture. The application (Nuru) as highlighted before was created to combat disease and pest susceptibility in cassava, one of the crops that feed half a billion Africans daily [49,50]. Farmers had difficulties in inspecting and managing every crop. As a result of the availability of AI, machine learning is now used to increase efficiency in the process of disease and pest control. "A machine learning model was trained using thousands of classified cassava images and the model was turned into an application where farmers can send images of their crop and receive information which gives them the ability to identify diseases with options available to manage the diseases" [49]. In this way, AI is assisting African agriculture to be sustainable which can help agriculture to feed the people. Similarly, Stanford University is utilizing machine learning to understand and predict crop yields in soybeans. Moreover, it is believed that machine learning can also assist in discovering places in developing and underdeveloped nations with food insecurity issues through satellite technology. The next section is outlining how AI can help in the education sector. All these developments are supported by various scholars who investigated the importance of AI in growth and development of economies for instance, Vincent et al. [34] argued that the world population is expected to increase to 2 billion in 2050, while the arable area is expected to grow by only 5\%. As a result, smart and efficient farming techniques powered by AI and machine learning are necessary to improve agriculture productivity. Eli-Chukwu [13] in another study also indicated that the application of AI has been evident in the agricultural sector. In the study where AI plays critical roles in solving some of the challenges affecting the agricultural sector in their endeavor to maximize yields. For instance, ensuring that there are proper soil treatment, disease, and pest infestation control, ensuring that big data requirements are solved, problems of low output can also be addressed, and knowledge gap between farmers and technology can be reduced.

\subsection{The Impact of AI on Education}

Poverty is usually associated with the inability of households to have formal education. The World Bank estimates that about 39\% of the world poorest do not have formal education. Aspects that hinder access to education for many households is purely the cost factor and capacity of the institutions of higher learning. Many institutions have a prescribed number of people they can accommodate [52]. AI can assist in raising the levels of education for the poor children the various methods which include adapted learning techniques using computer algorithms to encourage interaction with the learner as well as coming up with an education that is tailor-made for the needs of each learner [49]. Using $\mathrm{AI}$, it is highly possible to discover the specific learning need s of each learner and be able to satisfy these requirements using various methods of learning. In other unique circumstances, intelligent chat boards are used as tutors breaking the money barrier to education to pupils who come from poor areas which will help to address access issues finally be able to address inequality at the same time. One study by Mhlanga and Moloi [18] revealed that technology related to Industry 4.0 helped a lot during the COVID-19 social distancing for learners to be able to move on with education even during the lockdown. The study also found that technology can even increase access to education especially online education where space is not a limiting factor. One of the education projects where AI is assisting in 
education is through the social enterprise Eneza Education where AI is used in tutoring millions of rural students in Kenya, Ghana, and Côte d'Ivoire. In this way, AI is helping a lot in the achievement of quality education [49]. This also enables education to be inclusive and equitable creating and promoting lifelong learning opportunities for all $[49,53]$. Just like Mhlanga and Moloi [18], Chua and Valencia, [54] documented the importance of AI in education during the lockdown necessitated by the COVID-19 pandemic. Chua and Valencia, [54] found out that AI will play a significant role in education especially during the COVID-19 pandemic even though they argued that it will be difficult for AI to replace humans in administrating education.3.6. AI and Digital Financial inclusion.

Digital financial inclusion is viewed as a way of reaching out to the households who are not financially active, that is those who are not able to enjoy formal financial services that are designed to meet their needs [8,55]. Mhlanga, [8] argued that people who are excluded from the formal financial sector are women, youth, and the poor especially those staying in rural areas. Strusani and Houngbonon [43] argued that the traditional ways of reducing poverty and boosting shared prosperity are being subjected to technological disruptions where $\mathrm{AI}$ is changing the cost of access to products and services, changing how information is gathered, how products are made as well as how people interact. Strusani and Houngbonon [43] went on to argue that the challenges associated with development are increasingly becoming intertwined with technology where the goals of ending poverty and boosting shared prosperity are becoming critically dependent on harnessing the power of technologies like AI and at the same time looking for ways to minimize the risks associated with these technologies.

It has been established that in emerging markets countries are beginning to use basic AI to come up with solutions to critical challenges of development especially in the provision of financial services to underserved and unserved population [43]. The massive progress in basic machine learning algorithms and the growth in the number of technology users made it possible for emerging markets to use AI solutions like credit scoring and targeted advertising. Some early examples of AI being delivered in financial markets include the MoMo Kash in Cote d'Ivoire, M-Kajy in Madagascar, M-Shwari in East Africa, and Ant Financial in East Asia. M-Shwari made use of machine learning to come up with a prediction of the probability of default of potential borrowers making it possible for small loans to be delivered to 21 million Kenyans by the end of 2017.

Better data processing, a massive increase in access to credit is making AI drive innovation in financial services through relying on non-traditional data like mobile phone call records, mobile money transactions data, text messages and address books. Another important aspect of $\mathrm{AI}$ is that it reduces information asymmetry in contexts where borrowers lack credit history like first-time borrowers and the unbanked. In addition, AI is making financial services more affordable due to the automation of credit scoring which is one of the processes that was devoted to human resource in traditional financial institutions. Through machine learning algorithms, a large amount of mobile phone data can be parsed in delivering instantaneous credit scores to users in emerging economies. The scoring algorithm improves once the user is offered a loan by absorbing credit history data. Branch one of the fintech companies is one example where this approach is being used through offering microloans to first-time borrowers and customers without banking accounts in countries like Kenya, Nigeria, India, and Mexico.

In Africa, the popularity of digital financial inclusion increased when M-Pesa become one of the success stories in the payment innovations that started in Kenya [56]. M-Pesa is a mobile banking service lunched in 2007 by Safaricom the largest mobile phone operator in Kenya that allows users to store and transfer money through their mobile phones. In Asian countries like China digital financial inclusion is viewed as more than payment innovations which include digital investment, payments, and investment [56,57]. The importance of digital finance is its ability to utilize information communication technology (ICT) in increasing the scale and use of financial service by the poor and those excluded from the formal financial market $[8,58]$. The coming in of ICT and AI allowed financial 
inclusion to become digital and to allow groups of vulnerable people to be able to access finance [59]. Mhlanga, [8] agree with Wang and He, [56] that for business to be the activity to be successful when it is done with people at the bottom of the pyramid, radical innovations such as the use of $\mathrm{AI}$ is one of the requirements. The application of AI in digital financial inclusion makes it different from traditional financial inclusion because with digital financial inclusion, there is a massive reduction in transaction costs, especially in the rural areas because of lower marginal costs since with digital financial inclusion service provider necessarily do not need to have physical outlets [56]. The use of T AI and various ICT tools overcomes the major problem of traditional financial inclusion which is information asymmetry $[8,60]$.

Various online services and products provide a vast amount of information to customers which could not be accessible without the use of digital services [8]. Peric, [61] stated that the benefits of digital financial inclusion access to formal financial services by the poor people who were financially excluded, the other benefit is that digital financial inclusion helps to preserve the disposable incomes of the households because digital financial services and products are usually offered at a lower cost to the customer and the service provider. The use of AI also allows customers to be able to transact in irregular small amounts to assist them to manage their uneven incomes [8,62]. The other benefit of digital financial services is that it helps to reduce the risks of loss, theft, and other financial crimes posed by cash-based transactions $[8,63]$. Digital financial inclusion promotes economic empowerment by allowing the accumulation of assets for women, the youth, and the rural people which increases their economic participation $[8,64]$.

\section{Conclusions and Policy Recommendations}

Industry 4.0 is gaining a lot of attention particularly on its potential impact on humanity and the potential it has in changing how human beings live, work and how the economies work as well as how we are governed. This study investigated the influence of Industry 4.0 particularly AI on the attainment of Sustainable Development Goals (SDGs) with a direct focus on poverty reduction, industry, innovation, and infrastructure development in emerging economies. The study used content analysis and the results indicated that AI has a strong influence on the attainment of SDGs particularly poverty reduction in areas of relevant data collection through poverty maps, its ability to revolutionize agriculture, education, as well as the financial sector through digital financial inclusion. The study also found out that $\mathrm{AI}$ is equipping researchers to use satellite images to map poverty, to identify the regions where poverty is more concentrated. These initiatives are assisting in the identification of the number of poor people and the regions where these people are located making the poverty reduction initiatives more successful. Researchers are also using various robotics and AI programs like the "Google and Stanford University's Sustainability and Artificial Intelligence Lab", to come up with AI programs in agriculture that are helping to improve farming, through effective diseases detection, prediction of crop yields, and location of areas prone to a scarcity. In education, AI is improving education through various methods which include adapted learning techniques using computer algorithms to encourage interaction with the leaner among several other notable signs of progress in the sector. AI is also enabling massive infrastructure development, increase in access to information and knowledge as well as fostering innovation and entrepreneurship. The other aspect where AI is doing a lot is the improvement of the certainty and reliability of infrastructures like the transport sector making economic growth and development possible since one of the critical components of economic growth and development is an investment in infrastructure and innovation. Therefore, the study recommends that Governments in emerging economies, development institutions and other organizations that are striving in the achievement of the SDGs do invest more in AI as well as adopting and scaling up its use as it presents unlimited benefits.

The main limitation of the current study is the fact that some of the official complex hard data and peer-reviewed journal articles and books on the influence of AI on poverty, 
innovation, infrastructure development and sustainable development is still developing, and the study mainly focused on the influence of AI on the attainment of SDGs with a direct focus on poverty reduction, goal one, industry, innovation, and infrastructure development goal 9, in emerging economies. It will be interesting for future studies to investigate more on the differences between the influence of AI on SDGs in advanced economies and emerging economies in the Industry 4.0 debate.

Funding: This research received no external funding.

Institutional Review Board Statement: Not applicable.

Informed Consent Statement: Not applicable.

Data Availability Statement: Data available in a publicly accessible repository that does not issue DOIs. Publicly available datasets were used in this study.

Acknowledgments: We would like to extend our much appreciation to the University of Johannesburg and the Department of Accountancy for the administrative support for the work to be completed.

Conflicts of Interest: The author declares no conflict of interest.

\section{References}

1. Schwab, K. The Fourth Industrial Revolution. What It Means and How to Respond? 2016. Available online: https:/ /www.weforum. org/agenda/2016/01/the-fourth-industrial-revolution-what-it-means-and-how-to-respond/ (accessed on 28 June 2020).

2. Blinov, S. Causes of the British Industrial Revolution; Munich Personal RePEc Archive: Munich, Germany, 2014.

3. Dunga, H. The Impact of Technological Revolution on Poverty: A Case of South Africa; IDEAS, 2019. Available online: Ideas.repec.org (accessed on 20 January 2021). [CrossRef]

4. Allen, R.C. Explaining the British Industrial Revolution from the Perspective of Global Wage and Price History, helsinki.fi. 2006. Available online: http:/ / www.helsinki.fi/iehc2006/papers2/Allen52.pdf (accessed on 17 July 2020).

5. Crafts, N.F.R. The First Industrial Revolution: A Guided Tour for Growth Economists. Am. Econ. Rev. 1996, 86, 197-201. [CrossRef]

6. Schwab, K. The Fourth Industrial Revolution. 2016. Available online: https://law.unimelb.edu.au/_data/assets/pdf_file/0005 /3385454/Schwab-The_Fourth_Industrial_Revolution_Klaus_S.pdf (accessed on 28 June 2020).

7. Ooi, K.B.; Lee, V.H.; Tan, G.H.W.; Hew, T.S.; Hew, J.J. Cloud computing in manufacturing: The next industrial revolution in Malaysia? Expert Syst. Appl. 2018, 93, 376-394. [CrossRef]

8. Mhlanga, D. Industry 4.0 in finance: The impact of artificial intelligence (ai) on digital financial inclusion. Int. J. Financ. Stud. 2020, 8, 45. [CrossRef]

9. Deloitte. The Fourth Industrial Revolution Is Here Are South African Executives Ready? 2018. Available online: https:/ / www2.deloitte.com/za/en/pages/about-deloitte/articles/gx-preparing-tomorrow-workforce-for-the-fourthindustrial-revolution.html (accessed on 15 October 2020).

10. Berce, P. The fourth industrial revolution. Acad. J. Manuf. Eng. 2016, 5. [CrossRef]

11. Radziwill, N. The Fourth Industrial Revolution: Klaus Schwab; World Economic Forum: Geneva, Switzerland, 2016.

12. Smith, M.J. Getting value from artificial intelligence in agriculture. Anim. Prod. Sci. 2020, 60, 46. [CrossRef]

13. Eli-Chukwu, N.C. Applications of Artificial Intelligence in Agriculture: A Review. Eng. Technol. Appl. Sci. Res. 2019, 9, 4377-4383. [CrossRef]

14. Banwari, V. Fourth Industrial Revolution: Role of Education and Government. Int. J. Res. Eng. 2018, 8, 47-51.

15. Kravchenko, A.; Kyzymenko, I. The Fourth Industrial Revolution: New Paradigm of Society Development or Posthumanist Manifesto. Philos. Cosmol. 2019, 22, 120-128. [CrossRef]

16. Brown-Martin, G. Education \& the Fourth Industrial Revolution. In Proceedings of the 4th Industrial Revolution and its Impact on Education (ICERI), Seville, Spain, 1 August 2018; p. 7270. [CrossRef]

17. Soh, C.; Connolly, D. New Frontiers of Profit and Risk: The Fourth Industrial Revolution's Impact on Business and Human Rights. New Political Econ. 2020. [CrossRef]

18. Mhlanga, D.; Moloi, T. COVID-19 and the Digital Transformation of Education: What Are We Learning on 4IR in South Africa? Educ. Sci. 2020, 10, 180. [CrossRef]

19. Davis, N. What Is the Fourth Industrial Revolution? World Economic Forum, World Economic Forum. 2016. Available online: https:/ / www.weforum.org/agenda/2016/01/what-is-the-fourth-industrial-revolution/ (accessed on 5 May 2020).

20. Wisskirchen, G.; Biacabe, B.T.; Bormann, U.; Muntz, A.; Niehaus, S.; Soler, G.J.; von Brauchhitsch, B. Artificial Intelligence and Robotics and Their Impact on the Workplace; IBA Global Employment Institute: London, UK, 2017; p. 120.

21. Haenlein, M.; Kaplan, A. A brief history of artificial intelligence: On the past, present, and future of artificial intelligence. Calif. Manag. Rev. 2019, 61, 5-14. [CrossRef]

22. Buchanan, B.G.; Sarangi, S.; Armendariz, B.; Modruch, J. A (very) brief history of artificial intelligence. AI Mag. 2005, 26, 53-60. 
23. Benko, A.; Sik Lányi, C. History of Artificial Intelligence, Encyclopedia of Information Science and Technology, 2nd ed.; IGI Global: Hershey, PA, USA, 2011; pp. 1759-1762. [CrossRef]

24. Davis, P.; Sanchez-Martinez, M. Economic Theories of Poverty the Research. 2015. Available online: https://www.bl.uk/ britishlibrary/ \{\}/media/bl/global/social-welfare/pdfs/non-secure/e/c/o/economic-theories-of-poverty.pdf (accessed on 17 July 2020).

25. Davids, Y.D.; Gouws, A. Explaining Poverty: A Comparison between Perceptions and Conditions of Poverty in South Africa. 2010. Available online: http:/ / scholar.sun.ac.za/handle/10019.1/5318 (accessed on 1 May 2020).

26. Mhlanga, D. Financial Inclusion and Poverty Reduction: Evidence from Small Scale Agricultural Sector in Manicaland Province of Zimbabwe. 2020. Available online: http:/ / repository.nwu.ac.za/handle/10394/34615 (accessed on 1 August 2020).

27. Davis, P.; Sanchez-Martinez, M. A Review of the Economic Theories of Poverty. National Institute of Economic and Social Science. 2014. Available online: http:/ / bura.brunel.ac.uk/handle/2438/10008 (accessed on 17 July 2020).

28. Mhlanga, D.; Ndhlovu, E. Socio-economic Implications of the COVID-19 for Smallholder Livelihoods in Zimbabwe. Preprints 2020 [CrossRef]

29. Guterres, A. Report of the Secretary-General on SDG Progress 2019: Special Edition; United Nations Publications: Herndon, VA, USA, 2019; pp. 1-64. Available online: https://sustainabledevelopment.un.org/content/documents/24978Report_of_the_SG_on_ SDG_Progress_2019.pdf (accessed on 10 January 2021).

30. World Bank. Poverty Overview; World Bank: Washington, DC, USA, 2019. [CrossRef]

31. Moffitt, R.A.; Danziger, S.H.; Haveman, R.H. Understanding Poverty. Ind. Labour Relat. Rev. 2019, 57, 469. [CrossRef]

32. Mhlanga, D. Industry 4.0: The Challenges Associated with the Digital Transformation of Education in South Africa. In The Impacts of Digital Transformation; Aydın, O., Ed.; Efe Academy: İstanbul, Turkey, 2020; pp. 13-26; ISBN 978605-06499-1-8. e-ISBN: 978-605-06499-0-1344230555_.

33. Dharmaraj, V.; Vijayanand, C. Artificial Intelligence (AI) in Agriculture. Int. J. Curr. Microbiol. Appl. Sci. 2018, 7, $2122-2128$. [CrossRef]

34. Vincent, D.R.; Deepa, N.; Elavarasan, D.; Srinivasan, K.; Chauhdary, S.H.; Iwendi, C. Sensors drove ai-based agriculture recommendation model for assessing land suitability. Sensors 2019, 19, 3667. [CrossRef] [PubMed]

35. Zavadskaya, A. Artificial Intelligence in Finance: Forecasting Stock Market Returns Using Artificial Neural Networks; Hanken School of Economics: Helsinki, Finland, 2017; pp. 1-154.

36. Cossy-Gantner, A.; Germann, S.; Schwalbe, N.R.; Wahl, B. Artificial intelligence (AI) and global health: How can AI contribute to health in resource-poor settings? BMJ Glob. Health 2018, 3, 798. [CrossRef]

37. Kliestik, T.; Nica, E.; Musa, H.; Poliak, M.; Mihai, E.A. Networked, smart, and responsive devices in Industry 4.0 manufacturing systems. Econ. Manag. Financ. Mark. 2020, 15, 23-29. [CrossRef]

38. Peters, E.; Kliestik, T.; Musa, H.; Durana, P. Product decision-making information systems, real-time big data analytics, and deep learning-enabled smart process planning in sustainable Industry 4.0. J. Self Gov. Manag. Econ. 2020, 8, 16-22. [CrossRef]

39. Yigitcanlar, T.; Desouza, K.C.; Butler, L.; Roozkhosh, F. Contributions and Risks of Artificial Intelligence (AI) in Building Smarter Cities: Insights from a Systematic Review of the Literature. Energies 2020, 13, 1473. [CrossRef]

40. How, M.-L.; Cheah, S.-M.; Khor, A.C.; Chan, Y.J. Artificial Intelligence-Enhanced Predictive Insights for Advancing Financial Inclusion: A Human-Centric AI-Thinking Approach. Big Data Cogn. Comput. 2020, 4, 8. [CrossRef]

41. Elo, S.; Kääriäinen, M.; Kanste, O.; Pölkki, T.; Utriainen, K.; Kyngäs, H. Qualitative Content Analysis. SAGE Open 2014, 4. [CrossRef]

42. Colorado State University. An Introduction to Content Analysis Writing@CSU: Writing Guide. 1997. Available online: http: / / writing.colostate.edu/references/research/content/pop2a.cfm (accessed on 4 January 2021).

43. Strusani, D.; Houngbonon, G.V. The Role of Artificial Intelligence in Supporting Development in Emerging Markets. 2019. Available online: www.ifc.org/thoughtleadership (accessed on 20 October 2020).

44. Conde, M.L.; Twinn, I. How Artificial Intelligence is Making Transport Safer, Cleaner, More Reliable and Efficient in Emerging Markets. 2019. Available online: www.ifc.org/thoughtleadership (accessed on 10 January 2021).

45. Falah Al-Aroud, S. The Impact of artificial intelligence technologies on audit evidence. Acad. Acc. Financ. Stud. J. 2020, 24, 1-11.

46. United Nations. Goal 9 Department of Economic and Social Affairs. 2021. Available online: https://sdgs.un.org/goals/goal9 (accessed on 10 January 2021).

47. United Nations Development Programme. Goal 9: Industrial Innovation and Infrastructure UNDP. 2021. Available online: https://www.undp.org/content/undp/en/home/sustainable-development-goals/goal-9-industry-innovation-andinfrastructure.html (accessed on 20 September 2020).

48. Weber, I. How AI Is Being Used to Map Poverty. 2019. Available online: https://www.electronicspecifier.com/products/artificialintelligence/how-ai-is-being-used-to-map-poverty (accessed on 11 July 2020).

49. Decentralized AI Alliance Artificial Intelligence and Global Challenges-No Poverty by DAIA DAIA Medium. 2020. Available online: https://medium.com/daia/artificial-intelligence-and-global-challenges-a-plan-for-progress-fecd37cc6bda (accessed on 11 July 2020).

50. Schmidt, L. Artificial Intelligence and Poverty the Borgen Project, the Borgenp Project. Available online: https://borgenproject. org/tag/artificial-intelligence-and-poverty/ (accessed on 11 July 2020). 
51. Larson, K. Poverty and Shared Prosperity 2016, Imagining Equality in Nineteenth-Century American Literature; The World Bank: Washington, DC, USA, 2010. [CrossRef]

52. Wong, M. Using Satellites and AI to Help Fight Poverty in Africa Stanford News. Available online: https://news.stanford.edu/ 2020/05/22/using-satellites-ai-help-fight-poverty-africa/ (accessed on 11 July 2020).

53. Bennington-Castro, J. AI Is a Game-Changer in the Fight Against Hunger and Poverty. Here's Why, NBC News. 2017. Available online: https:/ / www.nbcnews.com/mach/tech/ai-game-changer-fight-against-hunger-poverty-here-s-why-ncna774696 (accessed on 11 July 2020).

54. Chua, C.; Valencia, L. The Role of Artificial Intelligence in Education Amidst of the COVID-19 Pandemic. 2020. Available online: https://www.researchgate.net/publication/343691393_The_Role_of_Artificial_Intelligence_in_Education_Amidst_of_ the_COVID-19_Pandemic (accessed on 17 May 2021).

55. Alameda, T. Data, Ai and Financial Inclusion: The Future of Global Banking—Responsible Finance Forum, Responsible Finance Forum BBVA 2020. Available online: https:/ / responsiblefinanceforum.org/data-ai-financial-inclusion-future-global-banking/ (accessed on 12 May 2020).

56. Wang, X.; He, G. Digital financial inclusion and farmers' vulnerability to poverty: Evidence from rural China. Sustainability 2020, 12, 1668. [CrossRef]

57. Van Hove, L.; Dubus, A. M-PESA and financial inclusion in Kenya: Of paying comes saving? Sustainability 2019, 11, 568. [CrossRef]

58. Lauer, K.; Lyman, T. Digital Financial Inclusion: Implications for Customers, Regulators, Supervisors, and Standard-Setting Bodies; Global Partnership for Financial Inclusion (GPFI): Seoul, Korea, 2015.

59. Visser, W.; Prahalad, C.K. The Fortune at the Bottom of the Pyramid: Eradicating Poverty trough Profits; Wharton School Publishing: Wharton, PA, USA, 2013; pp. 200-203. [CrossRef]

60. Gomber, P.; Koch, J.A.; Siering, M. Digital Finance and FinTech: Current research and future research directions. J. Bus. Econ. 2017, 87, 537-580. [CrossRef]

61. Peric, K. Digital financial inclusion. J. Paym. Strategy Syst. 2015, 9, 212-214. Available online: https:/ / www.ingentaconnect.com/ content/hsp/jpss/2015/00000009/00000003/art00001 (accessed on 11 May 2020).

62. Koh, F.; Phoon, K.F.; Ha, C.D. Digital Financial Inclusion in South East Asia. In Handbook of Blockchain, Digital Finance, and Inclusion; Elsevier: London, UK, 2018; pp. 387-403. [CrossRef]

63. Muneeza, A.; Arshad, N.A.; Arifin, A.T. The Application of Blockchain Technology in Crowdfunding: Towards Financial Inclusion via Technology. Int. J. Manag. Appl. Res. 2018, 5, 82-98. [CrossRef]

64. David-West, O. The Path to Digital Financial Inclusion in Nigeria: Experiences of Firstmonie, Journal of Payments Strategy \& Systems. Henry Stewart Publications. 2015. Available online: https://www.ingentaconnect.com/content/hsp/jpss/2016/00000 009/00000004/art00007 (accessed on 18 May 2020). 